Commentary on Pseudohallucinations in an Adolescent: Considerations for Diagnosis and Treatment in the Case of "Kate"

\title{
The Case of "Kate" and Her Pseudohallucinations from the Perspective of Interpersonal Defense Theory: An Example of Using Case Formulations as the Key Guide for Understanding Patients' Problems and Making Treatment Decisions
}

\author{
MICHAEL A. WESTERMAN ${ }^{\mathrm{a}, \mathrm{b}}$ \\ ${ }^{a}$ Department of Psychology, New York University \\ ${ }^{\mathrm{b}}$ Correspondence regarding this article should be addressed to Michael A. Westerman, Department of Psychology, \\ New York University, 6 Washington Place, Room 550, New York, New York 10003. \\ E-mail: michael.westerman@nyu.edu
}

\begin{abstract}
Shapiro, Bussing, and Nguyen’s (2014) case study of the treatment of Kate, a 16-year-old girl with pseudohallucinations, is instructive in two ways regarding the importance of going beyond a symptom-/diagnosis-based approach to psychotherapy. First, the case supports this point because the authors found it necessary to move away from their initial focus on Kate's hallucinations to successively broader viewpoints on Kate's problems, which involved shifting from a primary emphasis on medication to employing certain cognitive-behavioral interventions and then to taking a psychodynamically-oriented approach to Kate's individual therapy coupled with addressing family dynamics in adjunctive parent therapy. I maintain that in large measure we can attribute the gains that were made in the treatment to the authors' efforts (as therapist and supervisors) to move away from their initial symptom-based approach in these ways. However, I also maintain that the case study is instructive regarding the key point for a second, very different reason. I suggest that the authors could have moved further away from a symptom/diagnosis-based approach by adopting an approach that takes case formulation based on theoretical principles about processes as the basis for clinical work and uses those principles to organize the clinical data, including information about symptoms and diagnoses. I offer a tentative formulation of the case based on interpersonal defense theory (e.g., Westerman, 2011b; Westerman \& Muran, 2014; Westerman \& Steen, 2007) as an example of such an approach. I use that formulation as the basis for identifying limitations in the individual therapy with Kate and the work with Kate's parents and suggesting a number of ways in which the treatment might have been enhanced.
\end{abstract}

Key words: case formulation; interpersonal defense theory; symptom- and diagnosis-based approaches to therapy; psychodynamic therapy; cognitive-behavioral therapy; parenting therapy; case study; clinical case study 
The Case of "Kate" and Her Pseudohallucinations from the Perspective of

Interpersonal Defense Theory: An Example of Using Case Formulations as

the Key Guide for Understanding Patients' Problems and Making Treatment Decisions

M.A. Westerman

Pragmatic Case Studies in Psychotherapy, http://pcsp.libraries.rutgers.edu

Volume 10, Module 4, Article 3, pp. 271-286, 12-16-14 [copyright by author]

Shapiro, Bussing, and Nguyen (2014) have provided us with a fascinating and instructive case study. I find the case fascinating because it includes a number of very interesting facets, including an intriguing presenting problem that presented challenging diagnostic issues (Kate's pseudohallucinations), questions about the relationship between psychotherapeutic efforts and medication management, the use of both cognitive-behavioral and psychodynamically-oriented interventions, and efforts to work with the identified patient in individual therapy and also with her parents in an adjunctive treatment.

The case study is instructive because, as I read it, it illustrates the authors' struggle (as therapist and supervisors) to grapple with what they refer to as the "trend of 'superficial' discussion of symptomatology" (p. 254). I believe the case study shows that the authors initially approached the treatment in a manner that reflected this unfortunate symptom-based approach by focusing primarily on medication, but soon recognized the limitations of that approach for this case and endeavored to expand their focus in helpful ways - first by shifting to include cognitive-behavioral interventions and then by adopting a psychodynamically-oriented approach coupled with adjunctive parent therapy. I think we can attribute the gains that resulted from the therapy to this laudable effort to shift to approaches that were successively more adequate for addressing this particular clinical situation.

Nevertheless, it seems to me that the authors could have moved further beyond the limitations of a symptom-based (and diagnosis-based) perspective. In particular, I believe the treatment was conducted in a manner that did not reflect full appreciation of the crucial role case formulations can play in understanding patients' problems and guiding treatment. As a result, the case also is instructive for a very different, second reason-the limitations in the work help us see how we might take an approach based on case formulations in a more thoroughgoing manner.

The authors did employ formulations of the case, but I believe those formulations were too closely focused on symptoms and diagnoses. I believe case formulations should be based on theoretical principles about processes. We should use theoretical principles to organize the clinical data (including information about symptoms and diagnosis) and arrive at a formulation, not follow procedures or rules that make direct links from symptoms or diagnoses to formulations. I should note that it is possible to proceed in the manner I am recommending from any of a variety of theoretical viewpoints, as Persons (1991) argued in a classic article.

In this commentary, I will discuss the ways in which the authors moved beyond their initial symptom-based approach to the case. I also will offer my own thoughts about what might have been a more adequate formulation of the case and point out how that understanding of the case suggests differences in how the work might have been conducted. Along the way, I will offer some comments about some of the fascinating aspects of the case (e.g., the pseudohallucinations, the use of both cognitive-behavioral and psychodynamic interventions).

I should acknowledge that after a case is complete and one reads a detailed account of the whole therapy process it is relatively easy to form a picture of the case and come up with ideas 
The Case of "Kate" and Her Pseudohallucinations from the Perspective of

Interpersonal Defense Theory: An Example of Using Case Formulations as

the Key Guide for Understanding Patients' Problems and Making Treatment Decisions

M.A. Westerman

Pragmatic Case Studies in Psychotherapy, http://pcsp.libraries.rutgers.edu

Volume 10, Module 4, Article 3, pp. 271-286, 12-16-14 [copyright by author]

about other interventions that might have been helpful. Things are much more difficult when one is trying to understand a clinical situation in real time. Again, I commend the authors for being responsive to how things were going as they tried to help Kate and her parents. Their readiness to shift to broader frameworks enhanced the effectiveness of the overall treatment considerably. I also should acknowledge that the data provided by this single case study by no means demonstrate definitely the ideas I will put forward regarding (a) the general point that we should adopt an approach that treats case formulations based on theoretical principles about processes as the key guide for clinical work and use the theoretical principles to organize clinical data, including information about symptoms and diagnosis, or (b) the more specific point about the value of formulations based on interpersonal defense theory in particular. Nevertheless, the case study provides some useful data for evaluating these ideas.

\section{UNDERSTANDING THE CASE}

The authors focused a great deal on symptoms in their initial approach to the case. No doubt, this is understandable given the troubling and unusual nature of the symptom picture. By all means, it was necessary to try to make sense of Kate's hallucinations. Nevertheless, the author's excessive focus on that symptom at the outset of their work seems to be reflected by the fact that the reader does not learn almost anything else about Kate and her life besides features of the symptom picture until page 234 of the case study. Indeed, even when the authors say "Next we will review the individual and family psychological context relevant to crafting a psychodynamic formulation and treatment plan for Kate's hallucinations” (p. 231), they don't actually turn to that for several more pages.

But there are more important points to note here. One of these concerns the way in which the authors thought about the differential diagnosis issue related to Kate's hallucinations early in the treatment. For them, if the symptom was a pseudohallucination that was part of a "conversion disorder manifesting as psychiatric symptoms” (p. 228), then functional considerations come into play, whereas if it was part of a psychotic disorder, they do not. I agree that the differential diagnosis issue is important, but this stark contrast between problems that are and are not functional in nature seems misguided. If one takes a broader approach to conceptualizing cases, then functional considerations would play an important role in how one would proceed whatever the diagnosis. If the hallucinations were a symptom of a psychotic disorder, it would still be important to determine how the hallucinations interfered with Kate's functioning, the conditions that exacerbated and maintained the symptom, and so forth.

As I noted earlier, the authors shifted from a primary focus on medication to including cognitive-behavioral interventions as a major part of the treatment and then to a psychodynamic approach. Later, I will offer comments about their understanding of the case when they emphasized cognitive-behavioral interventions. The next point I want to make here concerns the formulation they arrived at when they decided to shift to psychodynamically-oriented efforts, which was the understanding of the case that guided much of their work for a large part of the treatment. 
The Case of "Kate" and Her Pseudohallucinations from the Perspective of

Interpersonal Defense Theory: An Example of Using Case Formulations as

the Key Guide for Understanding Patients' Problems and Making Treatment Decisions

M.A. Westerman

Pragmatic Case Studies in Psychotherapy, http://pcsp.libraries.rutgers.edu

Volume 10, Module 4, Article 3, pp. 271-286, 12-16-14 [copyright by author]

Although that formulation went beyond a focus on the symptom, it was driven by the symptom/diagnosis. Here, I am referring to the way the authors used Lukianowicz's (1969) study of children with non-psychotic hallucinations. The authors note (p. 231) that Lukianowicz identified “six possible 'aims and functions' of non-psychotic hallucinations.” They then go on to say that they developed a psychodynamic formulation of Kate's case based on this model. In fact, they lay out a formulation that directly follows along the lines of the six points, suggest that all six points apply in Kate's case, and say that they used this formulation "as the foundation of which both individual and parents' therapy were structured” (pp. 237-238). I certainly believe that it can be useful to review the literature on a particular symptom or diagnosis as an aid to arriving at a formulation of a given case, but the authors appear to have done something different: They treated past research on a symptom as the point-by-point basis for their formulation. In my view, distinctly different formulations are likely to apply in different cases all of which have a given symptom or diagnosis. We should not allow symptoms or diagnoses to drive our formulations or our treatment plans, although we should certainly take them into account. The process of arriving at a formulation should be approached as superordinate to assessing symptoms or determining diagnoses, not something that follows in lock-step order from symptom assessment and diagnosis.

My concerns about how the authors arrived at their understanding of the case notwithstanding, I believe that at least to some extent they recognized important features of Kate's problems. In particular, I believe they were on the mark when they pointed out that "Kate struggled to become a more independent, autonomous teenager” (p. 235). This was a very helpful observation. It seems clear that it contributed significantly to the gains that Kate made.

Nevertheless, once again, I think the authors' approach continued to be too focused on symptoms, or perhaps it is more accurate to say that their approach was too focused on a specific behavioral deficit. As I see it, to a large extent, the authors' concentrated too much on Kate's difficulties expressing anger. They returned to this specific issue repeatedly throughout their report of the case, and when they summarized the goals of treatment near the end of the case (p. 250), they note that one of their two goals was "focusing on and reinforcing more ageappropriate for behaviors for Kate, including the encouragement of more age-appropriate conflicts with parents, as the avoidance of the conflict was considered fuel for the pseudohallucinations.”

In my opinion, much of the work that was done helping Kate express her anger towards her parent was useful. However, I believe the issue of autonomy was the more basic problem to address. At times, helping an adolescent express anger towards his or her parents can contribute to gains on that issue, but there is not a one-to-one relationship between expressing anger and autonomy. Indeed, sometimes expressing anger can have the opposite effect, that is, it can work against the development of autonomy by promoting enmeshed family relationships. And in fact, the authors' description of how Kate would argue with her parents when they tried to reassure her about her hallucinations (p. 243) provides an example of this point. Also, there is much more to autonomy than expressing anger and, therefore, focusing on expressing anger can limit the range of autonomy-related gains that might be possible. 
The Case of "Kate" and Her Pseudohallucinations from the Perspective of

Interpersonal Defense Theory: An Example of Using Case Formulations as

the Key Guide for Understanding Patients' Problems and Making Treatment Decisions

M.A. Westerman

Pragmatic Case Studies in Psychotherapy, http://pcsp.libraries.rutgers.edu

Volume 10, Module 4, Article 3, pp. 271-286, 12-16-14 [copyright by author]

At least in part, I think the authors may have focused too much on Kate's difficulties expressing anger because of how they conceptualized a psychodynamic formulation. To be sure, different psychodynamically-oriented clinicians employ many different kinds of approaches to formulating cases (e.g., see Eells, 2010). In my opinion, some of those approaches are too oriented to "inner" experience. I believe the authors took that kind of approach to Kate's case in some ways. Although they sometimes discussed expressing anger from a more interpersonal perspective, they often treated it as if the issue was a problem of internal dynamics - as in a hydraulic model. Kate felt anger and so it was important to get it out because otherwise it would continue to take the form of violent hallucinations (e.g., see pp. 239). Similarly, they referred to Kate's feelings of guilt as the key reason why she didn't express anger, again treating the issue as if it primarily concerned internal dynamics. I agree that guilt was part of the picture, but I believe the main issue was Kate's concerns about how her parents would respond to her if she expressed her anger at them-and, more importantly, how they would respond to her if she behaved more autonomously in general.

\section{A Possible Alternative Formulation}

Based on the information provided in the case study, I can tentatively suggest a different formulation of Kate's problems. My understanding of the case does not focus primarily on internal dynamics, although it gives a place to those matters. Instead, it is based on an interpersonal perspective. Also, it moves away from focusing on the specific behavioral deficit of Kate's difficulties expressing anger and suggests that her problems involved complex interpersonal processes. Those processes are of a particular kind. I believe the processes in this case were an example of the general idea that "the solution is the problem," as the communications theorists (Watzlawick, Beavin, \& Jackson, 1967; also see Wachtel, 2008) put it. According to this viewpoint, psychological problems often are based on the ways in which people try to solve difficulties because those attempts at solving difficulties themselves create and maintain problems.

My tentative formulation of the case is based on interpersonal defense theory (e.g., Westerman, 2011b; Westerman \& Muran, 2014; Westerman \& Steen, 2007), an interpersonal reconceptualization of defense processes I have been developing. According to the theory, a case formulation should include the following components:

(1) the individual's central wished-for interpersonal response;

(2) a central feared response that the person is concerned might occur if he or she pursues the wish;

(3) a specific pattern of defensive behavior that attempts to do two things that are ultimately incompatible - pursue the wish, but also work to avoid the feared outcome, even though pursuing the wish opens up the possibility that the feared outcome will occur. Such defensive patterns are characterized by recurring discourse breaches, which I refer to as failures of coordination; 
The Case of "Kate" and Her Pseudohallucinations from the Perspective of

Interpersonal Defense Theory: An Example of Using Case Formulations as

the Key Guide for Understanding Patients' Problems and Making Treatment Decisions

M.A. Westerman

Pragmatic Case Studies in Psychotherapy, http://pcsp.libraries.rutgers.edu

Volume 10, Module 4, Article 3, pp. 271-286, 12-16-14 [copyright by author]

(4) positive outcomes distinct from the central wish that the defensive pattern actually leads to (it actually works against the central wish being realized, although it includes recurring attempts to pursue the wish); and

(5) negative outcomes distinct from the central fear that the defensive pattern actually promotes (it does successfully avoid the feared outcome).

This set of outcomes works to maintain the defensive pattern because even though the person's wish is not realized, he or she does avoid the fear and also realize positive outcomes (albeit positive outcomes that are distinct from the wish). Also, while the person encounters negative responses, those responses are not salient for the individual because they are different from the central fear.

It should be clear that case formulations of this sort provide a way to conceptualize clinical material in a manner that is theory driven. These case formulations can incorporate symptomatic behavior (and help us explain symptoms), but they go far beyond a symptomfocused consideration of a case.

I can briefly note that studies have provided support for tenets of interpersonal defense theory. Findings from a number of therapy process-outcome studies support the claim that defensive interpersonal behavior is characterized by recurring coordination failures (for a summary, see Westerman, 2011a, pp. 165-166). Among other things, results from those studies have suggested that associations between coordinating behavior and outcome are notably larger in magnitude than the correlations typically found between commonly used measures of the alliance and outcome (Hartmann, 2001; Westerman, Foote, \& Winston, 1995; Westerman, Frankel, Tanaka, \& Kahn, 1987; Westerman, Tanaka, Frankel, \& Kahn, 1986). In an experimental, non-clinical study, Westerman and Steen (2009) found support for the claim that conflict-ridden situations promote defensive, noncoordinating interpersonal behavior. Other experiments (Dahmen \& Westerman, 2007; Westerman \& Prieto, 2006) and several theorybuilding case studies (de Roten \& Westerman, 2014; Westerman, 2011b; Westerman \& Muran, 2014) provided support for the theory's tenets about how defensive interpersonal behavior affects interpersonal interaction outcomes regarding individuals' feared and wished-for responses and other negative and positive outcomes that are distinct from the wish and fear.

I have found it very helpful to use the Structural Analysis of Social Behavior (SASB; e.g., Benjamin, 1979) to make the differentiations between kinds of outcomes that are basic to the theory (e.g., to differentiate between a negative outcome that is a given person's central fear versus other outcomes that also are negative but distinct from that individual's key fear). In brief, SASB suggests that we can think of three broad kinds of negative outcomes: responses that are (1) neglectful/ignoring, (2) attacking, or (3) controlling in a hostile manner. SASB also identifies three broad types of positive outcomes, responses that (1) validate and encourage autonomy and independence, (2) are loving in a communing manner, and (3) are benignly guiding/managing.

I believe Kate's central wish was for other people-especially her parents - to encourage and validate her when she acted in an autonomous, independent manner. I think she was afraid 
The Case of "Kate" and Her Pseudohallucinations from the Perspective of

Interpersonal Defense Theory: An Example of Using Case Formulations as

the Key Guide for Understanding Patients' Problems and Making Treatment Decisions

M.A. Westerman

Pragmatic Case Studies in Psychotherapy, http://pcsp.libraries.rutgers.edu

Volume 10, Module 4, Article 3, pp. 271-286, 12-16-14 [copyright by author]

that if she behaved in ways to pursue that wish (i.e., by acting in autonomous, independent ways), her parents would neglect/ignore her. The case study does not include enough information about how Kate related to her parents on an ongoing day-to-day basis to form a firm idea about a possible defensive pattern. We do know that she often refrained from expressing anger. Because anger can be (although is not always) a way to assert independence, I suspect that she often refrained from expressing anger to avoid her fear of being neglected and ignored. Note that this is different from the idea that the main reason she didn't express anger was guilt. From the vantage point of interpersonal defense theory, her guilty feelings were part of the picture, but secondary to her interpersonal behavior. They supported her pattern of not expressing anger and, thereby, contributed to avoiding the feared interpersonal outcome. I should note that interpersonal defense theory suggests that Kate's day-to-day pattern of behavior with her parents probably also included elements that represented recurring attempts to put forward her viewpoint (e.g., act independently), but those attempts were probably hidden amidst other features of her behavior pattern that worked to largely “cancel out” the extent to which she clearly behaved autonomously.

I would view Kate's hallucinations as part of her defensive pattern. The hallucinations were a dysfunctional way in which Kate could present herself as something like "her own person.” Certainly, her parents didn't want her to have this problem. As the authors of the case study observed, this provided Kate with a way of covertly expressing her anger towards them, but I would say that, more basically, it offered a defensive way to be independent. However, it is important to note that the symptom was a compromise between her wish and her fear. Kate's hallucinations also worked against her parents ignoring her. Although they provided Kate with a way to be her own person, they also pulled for caretaking/managing/controlling responses by her parents because they showed that something was wrong with Kate. We see this, for example, in Kate's insistence on being diagnosed psychotic. To be sure, the fact that her hallucinations pulled for caretaking was quite clear - they involved voices telling Kate not to go into her own room and as a result she ended up sleeping in her parents' room.

More generally, the upshot of Kate's defensive behavior was that her parents (especially her father) took a benign caretaking stance toward her (positive responses distinct from her wish); and her parents (especially her mother) also took a hostile controlling stance toward her (negative responses distinct from her fear). She did not realize her wish-she did not receive encouragement and validation for her efforts at autonomy (such as they were given that they were parts of a highly defensive pattern) — but she avoided her fear (she was not ignored/neglected).

\section{KATE'S TREATMENT}

Given the points I have raised about how the authors understood the case, it is not surprising that I have questions about the treatment. I believe the therapy focused too much on symptoms and the behavioral deficit of Kate's difficulties expressing anger. Early in the treatment, the authors moved away from their initial highly symptom-based approach, but I believe it would have made a difference if they had adopted a still broader conceptualization of 
The Case of "Kate" and Her Pseudohallucinations from the Perspective of

Interpersonal Defense Theory: An Example of Using Case Formulations as

the Key Guide for Understanding Patients' Problems and Making Treatment Decisions

M.A. Westerman

Pragmatic Case Studies in Psychotherapy, http://pcsp.libraries.rutgers.edu

Volume 10, Module 4, Article 3, pp. 271-286, 12-16-14 [copyright by author]

the case. In what follows, I will discuss their approach to medication management, the individual therapy work with Kate, and the adjunctive treatment involving Kate's parents. Most of what I will say is based on my own tentative formulation of the case.

\section{Medication Management}

I agree with the authors (see p. 254) that Kate benefited from having a single provider conduct her therapy and manage her medication. In general, I think dividing up treatment between a psychiatrist managing medication and a psychotherapist conducting therapy often leads to problems due to a lack of close coordination between clinicians.

It is not at all clear to me what to do about this problem in general. It seems unlikely that many psychiatrists will have the opportunity to obtain extensive training in psychotherapy and go on to choose to conduct therapy with many of their patients. With regard to how psychologists might enter into a solution to this problem, although there are ongoing efforts to obtain prescribing privileges for psychologists, there is a real basis for concerns that they might then stop conducting therapy. Setting aside these wider concerns, Kate's case no doubt presented an especially clear need for coordinating medication management and therapy given the nature of her symptom and the diagnostic issues related to her hallucinations and also Kate's commitment to the diagnosis of psychosis. She was fortunate that a single provider, who was clearly committed to helping her, was able to address medication issues with her as part of her individual therapy.

\section{Individual Therapy with Kate}

\section{$\underline{\text { Cognitive-Behavioral Interventions }}$}

Relatively early in the treatment, the therapist employed relaxation training and selfcalming strategies and treated the hallucinations "as if they were cognitive distortions” (p. 232). Although the authors themselves came to question these initial efforts, it is worth noting that, in my opinion, there is quite a jump between holding the view that Kate had an anxiety disorder such that her hallucination could be considered panic attacks and/or a somatoform disorder (p. 231) and arriving at the decision to employ these particular intervention strategies, even if one is taking a cognitive-behavioral approach. To be sure, many practitioners who take a cognitivebehavioral approach might well proceed in exactly this way, but within a cognitive-behavioral framework there is room for case formulation, or what Kanfer and Saslow, in a classic 1965 article, called (and many others continue to call) "behavioral analysis" or "functional analysis" (e.g., Spiegler \& Guevremont, 2010). Indeed, Persons, who wrote the article I referred to earlier that advocated basing therapeutic efforts on case formulations, is a cognitive-behavioral therapist.

Some clarification of the preceding remarks is in order. In their report of this part of the case, the authors themselves talk about their approach at this point as if it was aimed directly at a symptom. However, in fact, the interventions they employed were based on a case formulation 
The Case of "Kate" and Her Pseudohallucinations from the Perspective of

Interpersonal Defense Theory: An Example of Using Case Formulations as

the Key Guide for Understanding Patients' Problems and Making Treatment Decisions

M.A. Westerman

Pragmatic Case Studies in Psychotherapy, http://pcsp.libraries.rutgers.edu

Volume 10, Module 4, Article 3, pp. 271-286, 12-16-14 [copyright by author]

that reflected a theoretical model of Kate's hallucinations. The authors based their thinking at this point in the treatment on a theory advanced by Richter et al. (2012) about panic attacks, according to which such attacks are caused by a

person's misinterpretation of normal bodily functions, the anxious apprehension of which results in an increasing cascade of somatic and anxious symptoms. In other words, the bodily symptom/sensation is real, but the meaning of the symptoms is misperceived by the individual, which results in worsening symptoms. (p. 231-232).

Shapiro et al. extended this line of thinking to Kate's case by viewing her hallucinations as the "bodily symptom/sensation" that she "misperceived" (p. 232).

Therefore, the authors did employ a formulation, but we can ask what the basis was for that understanding of the case. Although here again I should acknowledge that I have the benefit of hindsight, it seems to me that this formulation proceeded from a narrow conceptualization of the case that was too tightly linked to notions about symptoms and diagnosis. Specifically, I believe the authors were too narrowly focused on the fact that anxiety was a prominent feature of the case. By all means, it was important to arrive at an understanding of the anxiety, but many features of the case suggested different ways of thinking about Kate's anxiety and her other problems, including, among other things, the specific nature of the hallucinations and the fact that they resulted in Kate sleeping in her parents' room. I question the authors' diagnosis of panic attacks (as did the authors themselves following this part of the treatment), but I believe that even when that is the correct diagnosis in a given case, a formulation of the particular clinical situation should guide treatment decisions, not the diagnosis itself.

I should offer some further clarification about my thoughts regarding the authors' use of a cognitive-behavioral approach. Although the authors say that they shifted to a psychodynamic approach because they realized that they had to take into account functional considerations, that shift doesn't actually follow from the view that Kate's symptom played a functional role. Indeed, a key point of Kanfer and Saslow's (1965) classic article was that cognitive-behavioral therapists should base their efforts on a functional analysis of each particular case. Although I think there were considerable merits to the authors' decision to shift to a psychodynamic approach, I believe it may well have been possible to arrive at some other formulation of Kate's problems based on cognitive-behavioral theoretical principles that may have been helpful.

\section{$\underline{\text { Psychodynamic Approach }}$}

What about the psychodynamic approach the authors adopted? I believe that it served to expand the focus in ways that contributed greatly to the gains Kate made. Nevertheless, in my opinion, there are interesting questions to raise about this part of the treatment. There are two points here. For one thing, in a way that parallels my earlier suggestion that the authors' psychodynamic formulation focused too much on inner dynamics, I think their approach put too much emphasis on promoting insight in a manner that failed to place the "inner realm" in interpersonal context. 
The Case of "Kate" and Her Pseudohallucinations from the Perspective of

Interpersonal Defense Theory: An Example of Using Case Formulations as

the Key Guide for Understanding Patients' Problems and Making Treatment Decisions

M.A. Westerman

Pragmatic Case Studies in Psychotherapy, http://pcsp.libraries.rutgers.edu

Volume 10, Module 4, Article 3, pp. 271-286, 12-16-14 [copyright by author]

The authors approached the issue of Kate's difficulties expressing anger as if what was called for was helping Kate become aware of her anger towards her parents and realize that expressing her anger would lead to a reduction in her hallucinations. As they put it, the crucial insight for Kate to attain concerned "the correlation between her underlying anger and her hallucinations” (p. 248). As I see it, this formulation does not place Kate's anger in the interpersonal context of her life even though it refers to expressing anger at her parents because it fails to consider Kate's central interpersonal wish. As it stands, it amounts to a pro-catharsis position-Kate was angry and so for the sake of her internal psychic economy she needed to acknowledge and express that anger.

As I noted earlier, according to my case formulation, Kate’s difficulty expressing anger should not be viewed as an isolable part of the picture. It had a complicated relationship to her central wish - that her parents would validate and encourage her for behaving in autonomous and independent ways - and also to the other parts of the formulation I have suggested. We need to understand her "behavioral deficit" regarding expressing anger in terms of that broader, interpersonal framework.

Why was Kate angry? In part, as I see it, she was angry because her parents did not encourage her autonomy. In part, she also was angry because insofar as she directly (rather than defensively) pursued her wished-for response by her parents by behaving autonomously and independently (which she did rarely if at all), her parents ignored/neglected her. In addition, I believe that another part of the complicated answer to this question is that Kate's anger played a role in her defensive pattern, which pulled for both benign and hostile caretaking responses from her parents (positive outcomes distinct from her wish and negative outcomes distinct from her fear) — and which involved at times, as I noted earlier, expressing anger, not refraining from doing so (p. 242).

As I see it, the insight-oriented work could have been conducted in a way that would have helped Kate understand all of these aspects of her anger and, concomitantly, a complex set of ideas about whether and in what way she might express her anger. Such work could have helped her come to understand when and how she might express anger in ways that could contribute to realizing her wish rather than pulling for benign and hostile caretaking responses.

There also is a second point to consider. If we consider Kate's anger from the vantage point of the broader framework I am suggesting, it becomes clear that the insight-oriented work could have included efforts to help Kate understand her wish in ways that were separate from questions about expressing anger, because there is a great deal more to behaving autonomously and independently besides expressing anger.

For example, the authors report that at her last appointment, Kate talked about an argument with her mother in which she expressed her feelings but her mother did not change her position (page 250). Kate said she was proud about "standing up to her mother" but “disheartened” because she had not changed her mother's viewpoint. The therapist used this opportunity to point out that Kate’s anger wasn't as “dangerous” as Kate previously feared 
The Case of "Kate" and Her Pseudohallucinations from the Perspective of

Interpersonal Defense Theory: An Example of Using Case Formulations as

the Key Guide for Understanding Patients' Problems and Making Treatment Decisions

M.A. Westerman

Pragmatic Case Studies in Psychotherapy, http://pcsp.libraries.rutgers.edu

Volume 10, Module 4, Article 3, pp. 271-286, 12-16-14 [copyright by author]

because her mother didn’t have a "nervous breakdown.” Here, he was focusing on guilt, which was a feature of Kate's internal psychic economy related to anger. It seems to me that a different tack would have been more helpful. The therapist might have explored with Kate why she felt it was important for her mother to switch her position and whether she might be ok simply knowing that she presented her own viewpoint well. This approach might have helped Kate arrive at some insights about a different (more autonomous) way she could behave that would not involve continuing to argue with her mother.

There is nothing wrong with Kate wanting her mother to agree with her (Kate's) position in the argument, but (a) such agreement, if it were forthcoming, might not realize Kate's wish, because it could simply involve her mother indulging her or capitulating to her, and (b) in order to be validated for acting independently, a person actually needs to hold a position in such a manner that while he or she may want to convince someone else to adopt that position, the person feels alright about maintaining that viewpoint alone and does not feel compelled to argue/express anger. Paradoxically, one needs to be able to feel ok about holding the position by oneself to make it more likely that the other person will not simply agree but do so in a way that validates and encourages one's autonomy. The key point here is that at many junctures acting independently calls for doing something other than expressing anger.

\section{Active Interventions as Part of Psychodynamic Therapy}

In addition to the preceding comments about the therapist's insight-oriented efforts, I want to suggest that taking a psychodynamic approach can include employing active interventions. Many psychodynamically-oriented therapists use a wide range of interventions in their work. Wachtel (1997) offers an especially important example of this kind of approach. For him, probably the key defining feature of psychoanalytic therapy concerns how one conceptualizes cases. A variety of interventions might well prove useful so long as they are indicated by an appropriate type of case formulation.

In fact, the therapist did employ active interventions as part of his work with Kate and this was the case even after the point in the treatment when he shifted to a psychodynamic approach. I do not think we have to label that aspect of the later parts of the treatment "cognitivebehavioral.” In keeping with the authors' formulation of the case, the active interventions involved directive attempts aimed at encouraging Kate to express her anger to her parents. Much of this work was quite helpful in my opinion. For example, I think it contributed to Kate handling very effectively the incident about buying a towel rack for her dorm room notwithstanding her mother's objections (p. 249).

Here again, however, I believe the therapist's psychodynamically-based active interventions should have included more attention to helping Kate act independently in general, not just more able to express anger (and, again, expressing anger sometimes isn't acting independently at all). The report does include some examples of efforts of the sort I am recommending. For example, the authors note that at one point the therapist took the position that "only she could make herself feel better" (p. 243) and that at another point the therapist 
The Case of "Kate" and Her Pseudohallucinations from the Perspective of

Interpersonal Defense Theory: An Example of Using Case Formulations as

the Key Guide for Understanding Patients' Problems and Making Treatment Decisions

M.A. Westerman

Pragmatic Case Studies in Psychotherapy, http://pcsp.libraries.rutgers.edu

Volume 10, Module 4, Article 3, pp. 271-286, 12-16-14 [copyright by author]

encouraged Kate to make her own decisions about when to nap and when to finish her homework (p. 248). Additional active interventions might have been employed to encourage Kate to focus more in other directions besides her relationship with from her parents. For example, there might have been efforts to help Kate direct more energy to her own interests and activities, including her relationships with peers. Happily, Kate herself made gains in her peer relationships during the time she was in therapy, notwithstanding the fact that the therapist did not seem to address that domain of her life much at all. Note that I do not wish to suggest that Kate would have benefited by avoiding the issues in her relationship with her parents. In fact, efforts aimed at helping Kate develop in other spheres of her life might well have contributed to the efforts directed at helping her change her relationship with her parents.

\section{Therapeutic Relationship}

The authors do not discuss therapeutic relationship processes nor does it seem that the therapist explicitly addressed issues related to his relationship with Kate (via transference work) as part of his treatment approach. In my opinion, considerations about the therapeutic relationship are a very important part of psychodynamic therapy. For example, there is a great deal of difference between two possible approaches on the therapist's part-taking the stance of guiding Kate to express her anger because that is how she should behave versus working with Kate about expressing anger so that she would be ready to express her feelings towards her parents if she decided to do that. In fact, although the case report includes little relevant information, it seems that the therapist related to Kate in a way that encouraged and supported her autonomy, even though much of the time his specific interventions did not address that issue. I think this feature of the work probably contributed significantly to the gains Kate made as a result of her therapy.

\section{Therapy with Kate’s Parents}

I believe the authors' decision to include work with Kate's parents as part of the overall treatment was right on the mark. Other clinicians might have limited their efforts largely or even exclusively to Kate alone because she was the one with the symptom of concern (hallucinations) and the diagnosis. By contrast, recognizing that Kate's problems were situated in the context of her family system expanded the work well beyond a narrow symptom-/diagnosis-based approach.

As I see it, this aspect of the overall treatment contributed significantly to the gains that were made, but I have some comments about specific features of the work with the parents that are based on my understanding of the case. Here again, I should note that I realize that I have the benefit of hindsight, whereas the authors had to decide how to proceed in real time.

\section{Format of Parent Therapy}

The authors decided that the same therapist would conduct both Kate's individual therapy and the parent treatment. I think it would have been better for supporting Kate's 
The Case of "Kate" and Her Pseudohallucinations from the Perspective of

Interpersonal Defense Theory: An Example of Using Case Formulations as

the Key Guide for Understanding Patients' Problems and Making Treatment Decisions

M.A. Westerman

Pragmatic Case Studies in Psychotherapy, http://pcsp.libraries.rutgers.edu

Volume 10, Module 4, Article 3, pp. 271-286, 12-16-14 [copyright by author]

autonomy/independence to have different therapists conduct these two parts of the overall treatment (with the two therapists regularly consulting each other with the authorization of the members of the family). The format I am suggesting would instantiate treating Kate as an independent individual. The therapist would not be a direct bridge between Kate and her parents and, therefore, Kate could not look to the therapist to serve as a go-between. The authors' opted for a single therapist due to a concern about splitting (p. 238). Although I can see how having two separate providers for Kate's individual therapy and medication management might have led to splitting, that outcome doesn't seem very likely to me for the two therapies we are now considering.

I also think that it would have been better if the therapist had not started most "individual” sessions with Kate by asking the parent who brought her to the session to join them for the first few minutes. The therapist noted that he did this so that he could ask the parent for an update. I agree that it was important to get parent reports in this case, but this way of obtaining their views about what was going on worked against promoting Kate's independence. Given that the therapist was meeting with her parents, he could simply have asked them for their views in the parent sessions. If there had been different therapists conducting the individual therapy and the parent therapy, they could have routinely conferred.

As I see it, it would have been best to limit the times when Kate and one or both of her parents participated in a session to occasions that were expressly arranged in advance for the purpose of working on Kate's relationships with her parents. Given the treatment format I am suggesting, I think those sessions could have taken place as part of her individual therapy if and when Kate and her therapist decided that she could benefit from working on how to relate to her parents in a session with her therapist present.

\section{Focus of Therapy with Parents}

The therapist addressed two important aspects of family dynamics in his work with the parents. For one thing, in keeping with his formulation, he encouraged Kate's parents to be more accepting of her expressions of anger. In addition, his efforts were aimed at reducing what I would call parental positive responses distinct from Kate's wish and negative responses distinct from her fear, that is, reducing benign and hostile caretaking/controlling behavior by Kate's parents. As the authors put it, the therapist guided the parents away from efforts to "'protect' or 'save' Kate from situations which she could manage on her own” (p. 242). For example, the therapist encouraged Kate's father not to bring her home from school whenever she said she had a stomachache (p. 242) and he tried to help Kate's mother resist "the temptation to interfere with Kate's homework, grades, and social life” (p. 244).

Hence, it seems that the parent therapy focused less exclusively on Kate's difficulties expressing anger and more on autonomy and independence than was the case for Kate's individual therapy. I think the therapist might have gone one step further, however, if he not only tried to guide Kate's parents away from a caretaking/controlling stance, but helped them encourage and validate Kate's steps towards independence, that is, if he had intervened in ways 
The Case of "Kate" and Her Pseudohallucinations from the Perspective of

Interpersonal Defense Theory: An Example of Using Case Formulations as

the Key Guide for Understanding Patients' Problems and Making Treatment Decisions

M.A. Westerman

Pragmatic Case Studies in Psychotherapy, http://pcsp.libraries.rutgers.edu

Volume 10, Module 4, Article 3, pp. 271-286, 12-16-14 [copyright by author]

that might have led Kate's parents to respond to her in the ways she wished for according to my formulation of the case.

To be sure, the work with Kate's parents was a real challenge. It called for a good deal more than simple parent guidance because Kate's parents were not only in need of information about how to act towards their daughter. For different reasons, both Kate's mother and father were invested in the initial problematic pattern of family dynamics. Whatever else might have been part of the picture, the case report indicates that Kate's father's caretaking of his daughter was linked to difficulties of his own-most notably his inability to work-related to his alcoholism and health problems. The report also suggests that Kate's mother's behavior towards Kate was connected with her sense of failure at keeping her husband on track and, quite possibly, that it also was connected to limitations in her own development as an independent person. In addition, the family picture included problems in the marriage (see p. 244). Given these considerations, I think it would have been useful for Kate's parents and for Kate as well if the parent therapy had adopted a broader focus with an explicit agreement being reached at some point along the way between the therapist and Kate's mother and father that the goals of their work went beyond parenting issues.

One important specific development in the treatment overall occurred at least partly as a result of viewing the two therapies as too tightly linked together: the parent sessions were discontinued at the $21^{\text {st }}$ month. This occurred when Kate turned 18 and she "specifically declined having her parents participate in parent therapy sessions, saying 'I can do this on my own'” (p. 246). I should note that the authors themselves noted that this change in the overall treatment plan may have limited the gains Kate made (p. 251). Although it is possible to maintain that acceding to Kate's request supported her independence, I view this matter differently. It seems to me that treating this question as something for Kate to decide actually worked against supporting her independence because it implied that Kate's parents did not have a right to make their own decision about whether their therapy was something they wanted to continue given their own feelings about parenting Kate and their own feelings about other aspects of their lives as well. Events might not have taken this turn (i.e., discontinuing the parent therapy) if a different therapist had conducted the parent work, because then the sense in which the two treatments were separate might have been more clear.

\section{CONCLUDING COMMENTS}

Kate made significant gains during the course of the treatment. Most notably, she was able to leave home to go off to college. Also, Kate's hallucinations decreased in frequency and became less troublesome for her when they did occur. On a different front, Kate became friends with a new circle of peers. These gains are noteworthy, but there were indications that Kate's problems were not fully resolved. As the authors noted (p. 251), at the end of treatment Kate continued to experience hallucinations, she appeared to be suffering from an increase in somatic complaints (headaches and stomachaches), and she continued to worry excessively. Finally, in this brief review of the outcome of the case, I should note that the report does not include followup information and so we don't know what happened once Kate got to college. 
The Case of "Kate" and Her Pseudohallucinations from the Perspective of

Interpersonal Defense Theory: An Example of Using Case Formulations as

the Key Guide for Understanding Patients' Problems and Making Treatment Decisions

M.A. Westerman

Pragmatic Case Studies in Psychotherapy, http://pcsp.libraries.rutgers.edu

Volume 10, Module 4, Article 3, pp. 271-286, 12-16-14 [copyright by author]

In my commentary, I have suggested that it is useful to view this case study by Shapiro et al. (2014) as an excellent illustration of the idea that it is crucial to move beyond a symptom/diagnosis-based approach. I have suggested that in large measure we can attribute the gains that were made in the treatment to the authors' realization that their initial focus on Kate's hallucinations was too narrow. They expanded that focus considerably by determining that Kate was actually experiencing pseudohallucinations, shifting to cognitive-behavioral work and then to a psychodynamic approach in the individual therapy with Kate (although I raised questions about what actually constitutes "cognitive-behavioral” and "psychodynamic" therapy), and including an adjunctive therapy with Kate's parents based on recognizing the role played by family dynamics in Kate's problems.

However, I have maintained that the authors could have moved further away from a symptom-/diagnosis-based approach by adopting a perspective that takes case formulation based on theoretical principles about processes as the basis for clinical work and uses those principles to organize the clinical data, including information about symptoms and diagnoses. As an example of this approach, I offered a tentative formulation of the case based on interpersonal defense theory and used that formulation as a guide to commenting on the individual therapy and the work with Kate's parents. In particular, my tentative formulation suggested that instead of placing so much emphasis on the behavioral deficit of Kate's difficulties expressing anger, the authors could have focused on her wish to be encouraged and validated for acting in an autonomous and independent manner. It is possible that Kate might have made additional gains if the authors had taken such a tack.

I would like to conclude by lauding the authors for their efforts as therapist and supervisors. Unfortunately, the forces pushing for a symptom-/diagnosis-based approach are all too powerful at this time. The authors are to be commended for expanding their efforts beyond those narrow confines. As a result, they were of considerable help to Kate and they have provided the field with a case study that is instructive for researchers and practitioners about the need to take a broader approach.

\section{REFERENCES}

Benjamin, L. S. (1979). Structural analysis of differentiation failure. Psychiatry: Journal forthe Study of Interpersonal Processes, 42, 1-23.

Dahmen, B. A., \& Westerman, M. A. (2007). Expectations about the long-term consequences ofrecurring defensive interpersonal behavior. Journal of Research in Personality, 41, 1073-1090.

De Roten, Y., \& Westerman, M. A. (2014). Interpersonal defenses and resolution of allianceruptures: A theory-building case study. Submitted for publication.

Eells, T. D. (Ed.) (2010). Handbook of Psychotherapy Case Formulation (2 ${ }^{\text {nd }}$ edition). NewYork: The Guilford Press.

Hartmann. H. A. (2001). Clients' contribution to the alliance and the role it plays in outcome. (Doctoral dissertation, Adelphi University, The Institute of Advanced PsychologicalStudies, 2000.) Dissertation Abstracts International-B, 61/08, 4406. 
The Case of "Kate" and Her Pseudohallucinations from the Perspective of

Interpersonal Defense Theory: An Example of Using Case Formulations as

the Key Guide for Understanding Patients' Problems and Making Treatment Decisions

M.A. Westerman

Pragmatic Case Studies in Psychotherapy, http://pcsp.libraries.rutgers.edu

Volume 10, Module 4, Article 3, pp. 271-286, 12-16-14 [copyright by author]

Kanfer, F. H., \& Saslow, G. (1965). Behavioral analysis: An alternative to diagnostic classification. Archives of General Psychiatry, 12, 529-538.

Persons, J. B. (1991). Psychotherapy outcome studies do not accurately represent current models of psychotherapy. American Psychologist, 46, 99-106.

Shapiro, M.A., Bussing, R., \& Nguyen, M.L. (2014). Pseudohallucinations in an adolescent: Considerations for diagnosis and treatment in the case of "Kate." Pragmatic Case Studies in Psychotherapy, 10(4), Article 1, 227-259. Available: http://hdl.rutgers.edu/1782.1/pcsp_journal

Spiegler, M.D., \& Guevremont, D.C. (2010). Contemporary behavior therapy, 5th ed. Belmont, CA: Wadsworth.

Wachtel, P.L. (1997). Psychoanalysis, behavior therapy, and the relational world. Washington, DC: American Psychological Association.

Wachtel, P. L. (2008). Relational theory and the practice of psychotherapy. New York: The Guilford Press.

Watzlawick, P., Beavin, J. H., \& Jackson, D. D. (1967). Pragmatics of human communication: A study of interactional patterns, pathologies, and paradoxes. New York, NY: Norton.

Westerman, M.A. (2011a). Conversation analysis and interpretive quantitative research on psychotherapy process and problematic interpersonal behavior. Theory \& Psychology, 21, 155-178.

Westerman, M. A. (2011b). Defenses in interpersonal interaction: Using a theory-building case study to develop and validate the theory of interpersonal defense. Pragmatic Case Studies in Psychotherapy, 7(4), Article 3, 449-476. Available: http://hdl.rutgers.edu/172.1/pcspjournal

Westerman, M. A., Foote, J. P., \& Winston, A. (1995). Change in coordination across phases of psychotherapy and outcome: Two mechanisms for the role played by patients' contribution to the alliance. Journal of Consulting and Clinical Psychology, 63, 672-675.

Westerman, M. A., Frankel, A. S., Tanaka, J. S., \& Kahn, J. (1987). Client cooperative interview behavior and outcome in paradoxical and behavioral brief treatment approaches. Journal of Counseling Psychology, 34, 99-102.

Westerman, M. A., \& Muran, J. C. (2014). Using a discourse-analytic method based on interpersonal defense theory to examine therapeutic alliance processes. Manuscript submitted for publication.

Westerman, M. A., \& Prieto, D. M. (2006). Expectations about the short-term functional role played by defensive behavior in interpersonal interactions. Journal of Research in Personality, 40, 1015-1037.

Westerman, M. A., \& Steen, E. M. (2007). Going beyond the internal-external dichotomy in clinical psychology: The theory of interpersonal defense as an example of a participatory model. Theory \& Psychology, 17, 323-351.

Westerman, M. A., \& Steen, E. M. (2009). Revisiting conflict and defense from an interpersonal perspective: Using structured role plays to investigate the effects of conflict on defensive interpersonal behavior. Psychoanalytic Psychology, 26, 379-401.

Westerman, M. A., Tanaka, J. S., Frankel, A. S., \& Kahn, J. (1986). The coordinating style construct: An approach to conceptualizing patient interpersonal behavior. Psychotherapy, 23, 540-547. 